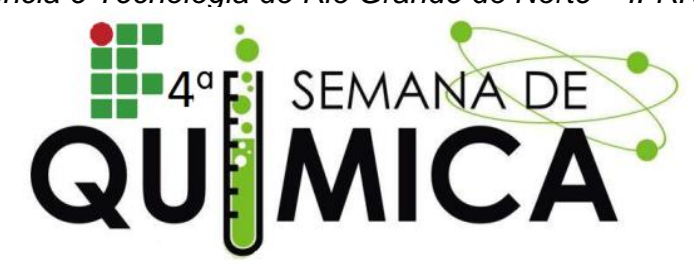

\title{
CONCEITO DE POLÍMEROS NOS LIVROS DIDÁTICOS APROVADOS PELO PNLD PARA O TRIÊNIO 2015 Á 2018
}

*NASCIMENTO, K.K. V. PEREIRA, L. H. S. ALVES, M .V. S

(katiakarinkarin@gmail.com/souzalay19@gmail.com/marcelo.santos@ifrn.edu.br) (IFRN - CN)

Palavras Chave: PNLD, POLÍMEROS, LIVRO DIDÁTICO.

\section{INTRODUÇÃO}

O ensino de química apresenta dificuldades de ensino-aprendizado para os alunos. Diante disso, uma ferramenta utilizada e de fácil acesso aos alunos é o livro didático. Segundo o PNLD 2015, o livro didático é uma ferramenta indispensável para os docentes, pois auxilia na transmissão de conhecimento para os alunos, sendo um material acessível para os mesmos (Brasil, 2015). Dessa maneira, iremos analisar alguns pontos em destaque no PNLD 20152018 para avaliar um dos conteúdos abordados nos livros de $3^{\circ}$ série do nível ensino médio.

\section{METODOLOGIA}

Os livros analisados serão aqueles aprovados no PNLD 2015 para o ensino de Química:

\begin{tabular}{|l|l|}
\hline $\begin{array}{l}\text { Livro } \\
\text { A }\end{array}$ & $\begin{array}{l}\text { Química: Marta Reis Marques da Fonseca, Ed. } \\
\text { Ática, edição 2013. }\end{array}$ \\
\hline $\begin{array}{l}\text { Livro } \\
\text { B }\end{array}$ & $\begin{array}{l}\text { Química: Eduardo Fleury Mortimer e Andréa } \\
\text { Horta Machado, Ed Scipione, 2a edição 2013. }\end{array}$ \\
\hline $\begin{array}{l}\text { Livro } \\
\text { C }\end{array}$ & $\begin{array}{l}\text { Química Cidadã: Wildson Luiz Pereira dos } \\
\text { Santos e Gerson de Souza Mol (Coords.), Ed. }\end{array}$ \\
\hline $\begin{array}{l}\text { Livro 2a edição 2013. } \\
\text { D }\end{array}$ & $\begin{array}{l}\text { Ser Protagonista: Murilo Tissoni Antunes, Ed. } \\
\text { SM, 2a edição 2013. }\end{array}$ \\
\hline
\end{tabular}

Quadro I: seleção dos livros aprovados pelo PNLD 2015.

A análise foi feita seguindo algumas questões guias que envolvem o conceito de polímeros, das quais menciona: Qual a definição de Polímeros? Qual o tema utilizado para contextualização? Quais os conceitos que antecedem o conceito de Polímeros? Quais os recursos didáticos utilizados na abordagem do conceito de Polímeros? Atividades propostas para o conceito de polímero? (Adaptado. Brasil, 2015).

\section{RESULTADOS E DISCUSSÕES}

Diante dos pontos analisados como referência no Plano Nacional dos Livros Didáticos (PNLD 2015), foi observado contextos distintos de cada um dos quatro livros. Alguns apresentam pontos negativos de difícil compreensão da linguagem especifica do que alguns livros apresentam, e pontos positivos o qual relaciona os conteúdos ao cotidiano em sua abordagem metodológica, em que todos tem uma importância em seu contexto no processo de ensino-aprendizagem, mostrando que ambos precisam melhorar nos pontos descritos na metodologia.

\section{CONCLUSÃO}

Diante disso as questões analisadas propiciam para que o estudo dos livros didáticos, melhorem em alguns aspectos, para uma melhor compreensão dos conceitos, isso foi o caso dos quatro livros analisados que mostram pontos positivos e negativos de ambos, contribuindo para que o próxima análise do PNLD disponha de melhoria através dessas análises melhorando as próximas edições.

\section{REFERÊNCIAS}

1. PNLD 2015. Guia dos Livros Didáticos Química. Ministério de Educação, Secretária de Educação Básica, 2014. 
